\title{
DiGeorge syndrome with isolated aortic coarctation and isolated ventricular septal defect in three sibs with a $22 q 11$ deletion of maternal origin
}

\author{
D I Wilson, I E Cross, J A Goodship, S Coulthard, A H Carey, P J Scambler, H H Bain, \\ A S Hunter, P E Carter, J Burn
}

\begin{abstract}
DiGeorge syndrome was diagnosed in an infant who had an interrupted aortic arch, hypoparathyroidism, and low $T$ lymphocyte numbers. Two siblings had heart defects that are not commonly described in DiGeorge syndrome (a membranous ventricular septal defect and coarctation of the aorta respectively). These siblings did not have evidence of thymic dysfunction or hypoparathyroidism. Chromosome analysis showed that the mother, whose cardiovascular examination was normal, and her three offspring with heart defects had a 22 q11 interstitial deletion, which was confirmed by molecular analysis.

This family suggests that 22 q11 deletions can cause apparently isolated heart defects and that the range of these defects may be wider than previously recognised. Once the genes that are deleted in this family are characterised they will be useful candidate genes in the investigation of isolated cardiac malformations.
\end{abstract}

Department of

Human Genetics,

University of

Newcastle upon Tyne

D I Wilson

I E Cross

J A Goodship

$S$ Coulthard

J Burn

Department of

Biochemistry and

Molecular Genetics,

St Mary's Hospital

Medical School,

London

A H Carey

P J Scambler

Department of

Paediatric Cardiology,

Freeman Hospital,

Newcastle upon Tyne

H H Bain

A S Hunter

Department of

Paediatrics, West

Cumberland Hospital,

Cumbria

P E Carter

Correspondence to

Dr D I Wilson, Department

of Human Genetics,

19 Claremont Place,

Newcastle upon Tyne

NE2 4AA.

Accepted for publication

4 July 1991
Though genetic defects are known to be a major cause of heart malformation the precise relation is poorly understood. One approach to the search for the genetic basis of heart defects is via syndromes with known chromosomal localisations.

In 1965 DiGeorge described congenital absence of the thymus and parathyroid glands found at necropsy in three children, and in a fourth child with congenital hypoparathyroidism and defective cellular immunity. ${ }^{1}$ In subsequent years it was recognised that congenital heart defects and a characteristic facial appearance were often associated with these findings. ${ }^{23}$ The combination of aplasia, or hypoplasia, of the thymus and parathyroid glands together with cardiac defects and dysmorphic facial features became known as DiGeorge syndrome.

The cardiac defects most commonly found in DiGeorge syndrome are interrupted aortic arch type B and truncus arteriosus. ${ }^{4-6}$ Type B interrupted aortic arch occurs in over $30 \%$ of cases of DiGeorge syndrome, truncus arteriosus in $25 \%$ of cases, and tetralogy of Fallot in $20 \% .^{7}$ An aberrant right subclavian artery arising from the descending aorta, a right sided aortic arch, and transposition of the great arteries are also well recognised cardiac abnormalities in DiGeorge syndrome.

The dysmorphic features seen in the syndrome are hypertelorism with short palpebral fissures, a small mouth and short philtrum, retrognathia, and low set, posteriorly rotated ears.

In 1981 de la Chapelle described a family with members carrying a balanced chromosome rearrangement, $t(20 ; 22)(\mathrm{q} 11 ; \mathrm{q} 11)$. Four children in this pedigree had DiGeorge syndrome; all had the same unbalanced translocation products resulting in monosomy for 22pter-22q11 and trisomy for 20 pter-20q11. ${ }^{8}$ The following year a further three unrelated patients with DiGeorge syndrome were reported who were monosomic for 22pter-22q11. ${ }^{9}$ Two of these children had inherited unbalanced forms of familial translocations and the third child had a de novo unbalanced translocation. There have been additional reports of affected children with unbalanced translocations with chromosome 22 involvement. ${ }^{10-13}$ The minimal region of deletion common to all these cases is 22q11. More recently a child with DiGeorge syndrome and an interstitial deletion of 22q11 has been described. ${ }^{14}$

We report a family in which an interstitial deletion of $22 \mathrm{q} 11$ was transmitted from a mother to three offspring. One child has the complete DiGeorge syndrome phenotype. The remaining three individuals with the cytogenetic deletion have a range of clinical features but none fulfils the diagnostic criteria of DiGeorge syndrome.

\section{Patients and methods}

CASE 1

The proposita, the youngest member of the sibship, was born at 40 weeks' gestation and weighed $2.46 \mathrm{~kg}$. She had bilateral talipes equinovarus and a dysmorphic appearance with small mouth, short philtrum, and low set posteriorly rotated ears (fig 1). She became unwell at three days of age with poor peripheral perfusion and cardiac failure. Echocardiography showed an interrupted aortic arch type $B$ and a perimembranous ventricular septal defect. The total blood $\mathrm{T}$ lymphocyte count was low $\left(580 \times 10^{6} / 1\right.$, reference values $\left.>1500 \times 10^{6} / 1\right)$. Surgical repair and patch closure of the ventricular septal defect were performed. The postoperative period was complicated by necrotising enterocolitis and 
Figure 1 Small mouth and short philtrum in case 1 .

Figure 2 Short philtrum and narrow upslanting palpebral fissures in the mother.

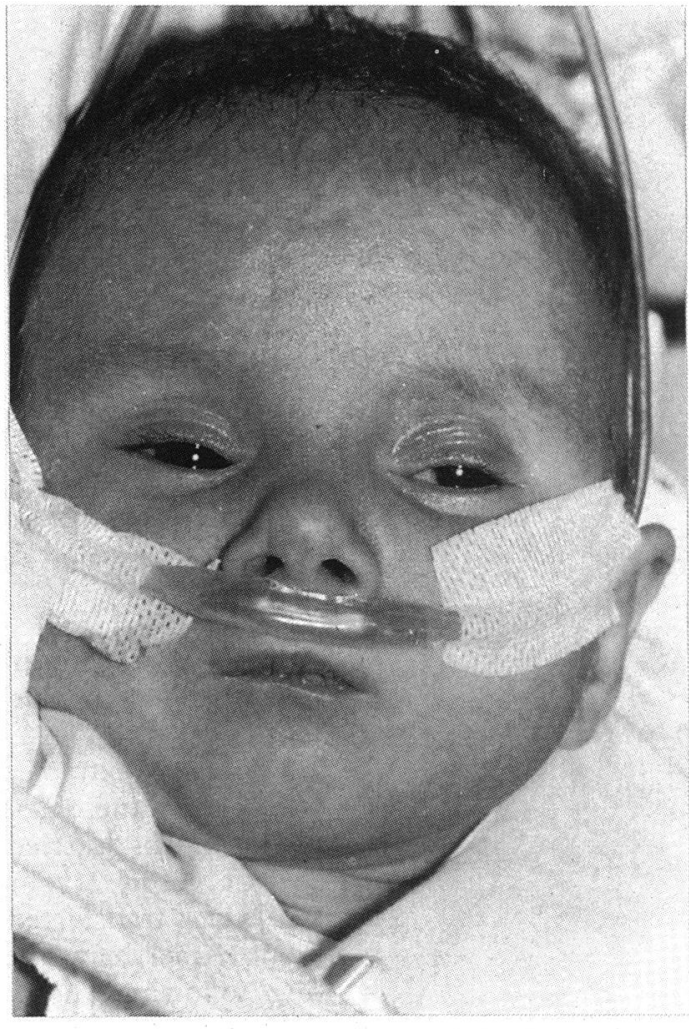

declined further cardiological investigation. The mother was mildly dysmorphic having a short philtrum and narrow upslanting palpebral fissures (fig 2). Her four pregnancies were uncomplicated. Alcohol and drug ingestion during these pregnancies was denied and there was no history of pregnancy loss. The first child, born at 40 weeks' gestation weighing $3.5 \mathrm{~kg}$, was well and not dysmorphic. Their other two children had undergone surgical correction of heart malformations.

CASE 2

The second child was born at 41 weeks' gestation and weighed $2.53 \mathrm{~kg}$. He was dysmorphic, with narrow palpebral fissures and a high arched palate (fig 3), and had a right inguinal hernia. He presented with failure to thrive at two months of age and was found to have a membranous ventricular septal defect. This was confirmed by echocardiography and cardiac catheterisation. The ventricular septal defect required surgical repair when he was 4 years old. At 11 years of age he had had no symptoms of immunodeficiency or hypocalcaemia and his serum calcium concentration and total blood $T$ lymphocyte count were within normal limits.

CASE 3

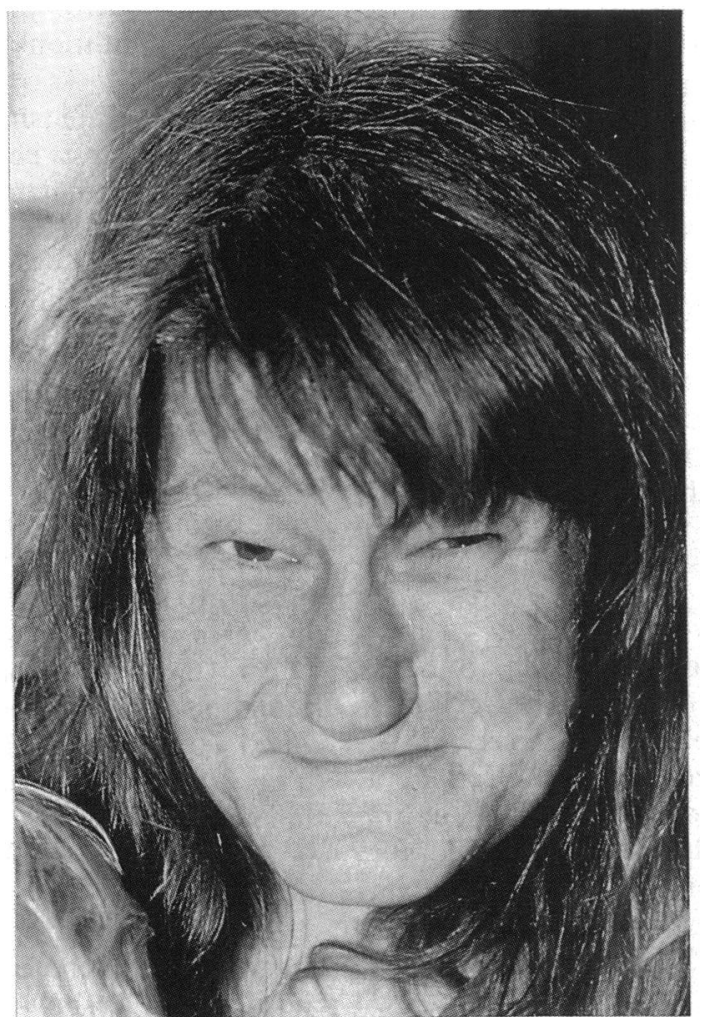

The third child was born at 39 weeks' gestation and weighed $2.9 \mathrm{~kg}$ (fig 4). He had a small mouth, poorly modelled philtrum, overfolded pinnae, and bilateral talipes equinovarus. Bilateral inguinal hernias were repaired at 7 days of age. He did not thrive postoperatively and coarctation of the aorta and a persistent ductus arteriosus were diagnosed when he was 4 weeks old. At operation a hypoplastic isthmus was identified between the left carotid

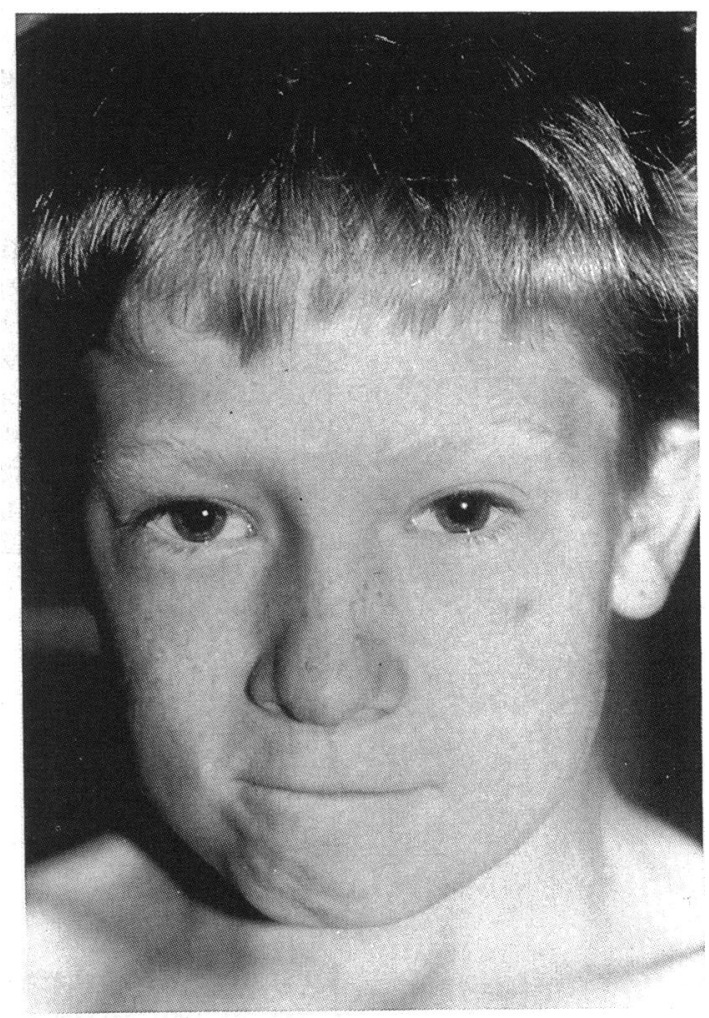

(1) seizures (total $1.15 \mathrm{mmol} / 1$, normal range $2 \cdot 28-2.65 \mathrm{mmol} / \mathrm{l}$ ). She was given calcium supplementation until she was six weeks old. Renal ultrasound showed that she had no left kidney.

The parents were unrelated white Europeans. Neither had a history of frequent infections, seizures, or heart disease in childhood. Clinical examination of the cardiovascular system in both parents was normal; they 
Figure 4 Small mouth and poorly modelled philtrum in case 3.
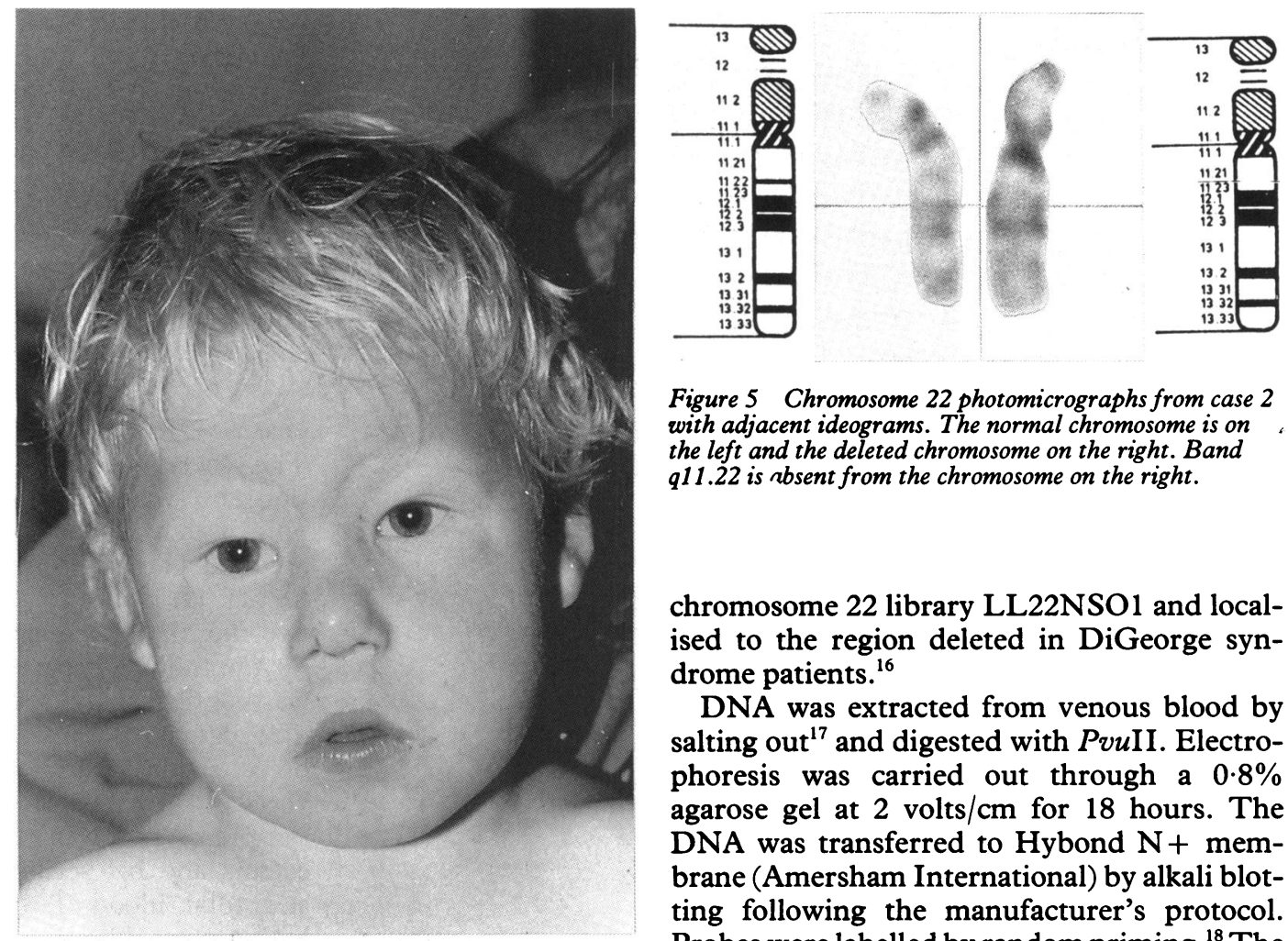

Figure 5 Chromosome 22 photomicrographs from case 2 with adjacent ideograms. The normal chromosome is on the left and the deleted chromosome on the right. Band q11.22 is absent from the chromosome on the right.

chromosome 22 library LL22NSO1 and localised to the region deleted in DiGeorge syndrome patients. ${ }^{16}$

DNA was extracted from venous blood by salting out ${ }^{17}$ and digested with PvuII. Electrophoresis was carried out through a $0.8 \%$ agarose gel at 2 volts $/ \mathrm{cm}$ for 18 hours. The DNA was transferred to Hybond $\mathrm{N}+$ membrane (Amersham International) by alkali blotting following the manufacturer's protocol. Probes were labelled by random priming. ${ }^{18}$ The filter was hybridised with KI-182.3 and a rhodopsin control probe. Hybridisation and washing conditions were as described previously. ${ }^{16}$

The signal intensity with $\mathrm{KI}-182.3$ in the father and eldest child in the sibship was comparable to that in equally loaded control lanes. The KI-182.3 signal intensity in the mother and in cases 1,2 , and 3 was half the intensity in normal control tracks with equal DNA loading (fig 6). This was confirmed by laser densitometry. after the thoracotomy. Blood glucose, calcium, and magnesium were normal at the time of these seizures and no cause was identified. At the age of 4 he was well and his $T$ lymphocyte and calcium values were within normal limits.

\section{CYTOGENETIC STUDIES}

Chromosome preparations were made from 72 hour phytohaemagglutinin stimulated cell cultures from peripheral blood from members of the family. Cultures were synchronised by a pulse of thymidine administered 21 hours before harvesting. Colcemid was added for only 8-15 minutes before harvesting to obtain chromosomes of sufficiently high resolution to visualise band 22q11.22-that is at least 850 bands per haploid set. ${ }^{15}$ Preparations were G banded with trypsin and Leishman stain.

Chromosome analysis showed apparently normal karyotypes in the father and eldest daughter of the family. The mother and the remaining three children (cases 1,2 , and 3 ) had a small interstitial deletion of the proximal long arm of chromosome 22, del(22)(q11.21q11.23) (fig 5).

\section{MOLECULAR STUDIES}

Quantitative Southern blot analysis was carried out with the probe KI-182.3 (D22S134) which was generated from the flow-sort-enriched

\section{Discussion}

Four members of this family have an interstitial deletion at chromosome 22q11. The youngest child fulfills the clinical criteria for the diagnosis of DiGeorge syndrome. She had a typical heart defect, hypocalcaemia, low $\mathrm{T}$ lymphocyte numbers, and the dysmorphic features associated with the condition. Her mother and two of her siblings have the same cytogenetic deletion but do not have DiGeorge syndrome.

The molecular analysis of DNA from this family confirms the cytogenetic findings. The $\mathrm{KI}-182.3$ signal intensity in the father and normal sister were equivalent to the normal control sample showing the presence of two copies of the DNA sequence. The signal intensity in the mother, proposita, and her siblings with congenital heart disease was half that in the equivalent normal control track showing that they have only one copy of KI-182.3 (D22S134). Thus a deletion of chromosome 22q11 was demonstrated by two independent methods in the proposita, her mother, and the two siblings with congenital heart disease.

A common feature in the range of cardiovascular malformations in DiGeorge syndrome is a disturbance of the outflow tract of the embryonic heart or impaired development of 


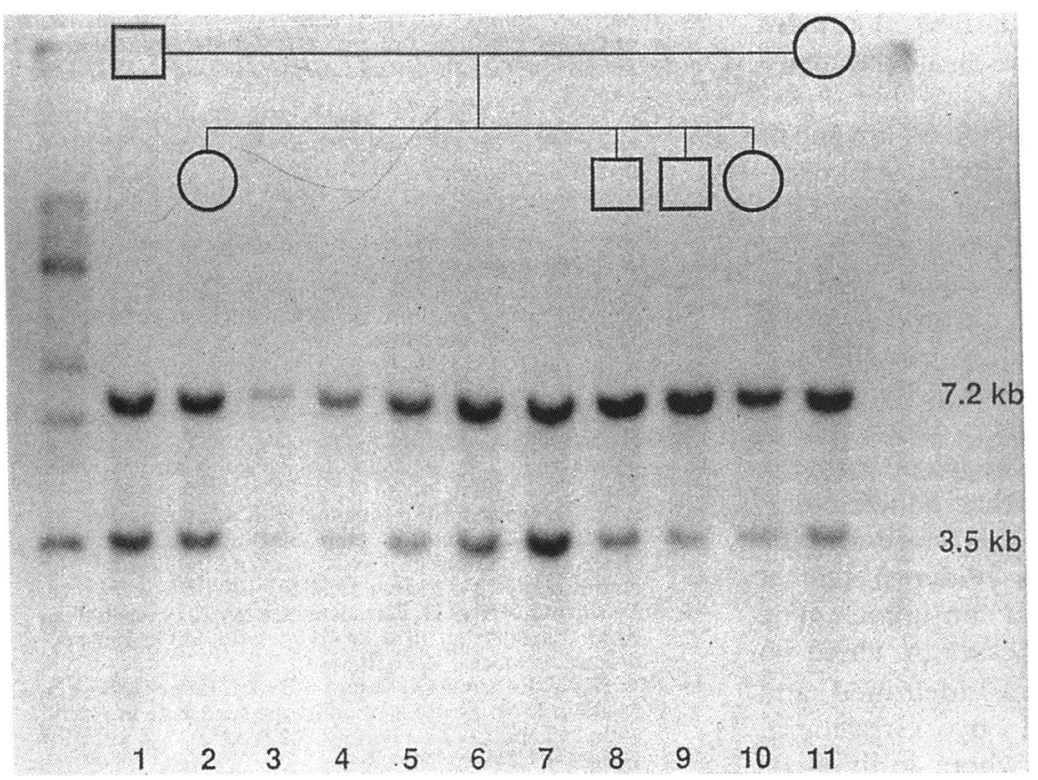

Figure 6 Autoradiograph showing the quantitative Southern blot analysis. The KI-182.3 band is at $3 \cdot 5 \mathrm{~kb}$ and the control band at $7 \cdot 2 \mathrm{~kb}$. Tracks 3 to 7 contain $3 \mu \mathrm{g}$ $5 \mu \mathrm{g}, 7 \mu \mathrm{g}, 9 \mu \mathrm{g}$, and $11 \mu \mathrm{g}$ of DNA from a normal control. Track 1 is DNA from the father, track 2 from the oldest (normal) child in the sibship, track 8 from case 2, track 9 from case 3, track 10 from case 1 and track 11 from the mother. The intensity of the $K I-182 \cdot 3$ band in the father and eldest child is comparable with that in the normal control. The intensity of the KI-182.3 band is clearly reduced in the mother, case 1 , case 2 , and case 3. did not have important thymic involvement.

De la Chapelle described four affected individuals in one family in which a $20 ; 22$ translocation was segregating. ${ }^{8}$ Greenberg et al reported a case of $\mathrm{DiGeorge}$ syndrome associated with partial monosomy of $22 \mathrm{q}$ resulting from an unbalanced translocation, $\operatorname{der}(22), t$ $(4 ; 22)(\mathrm{q} 35.2 ; \mathrm{q} 11.2) .^{20}$ The first child in the sibship described by Greenberg had died at two months and was thought to have had a congenital heart defect; the second child was found at necropsy to have truncus arteriosus, thymic aplasia and parathyroid hypoplasia; and the third child was the proband. The mother was found to carry the same unbalanced chromosome rearrangement. Cardiovascular examination was normal but she was noted to have hypertelorism and on investigation she had low $\mathrm{T}$ lymphocyte numbers and a reduced response to $T$ cell mitogens compared with a normal control. Augusseau et al reported a family in which a phenotypically normal female with a balanced translocation $(46, \mathrm{XX}, \mathrm{t}(2 ; 22)$ (q14; 11 )) had a child with the same karyotype with hypertelorism, micrognathia, severe coarctation of the aorta, and hypocalcaemia. ${ }^{19}$ The woman's sister carried the same translocation and had one pregnancy terminated because of a fetal cardiac malformation. It is possible that a further chromosome rearrangement may have occurred and led to the different phenotype in the children reported by Augusseau and Greenberg. However, it is more likely that the same cytogenetic abnormality resulted in differing phenotypes within families-both in these families and in the family we have presented here.

There have been previous reports of DiGeorge syndrome occurring in more than one individual in families with no detectable cytogenetic abnormality. Rohn et al described a family in which a father and two male offspring had features of DiGeorge syndrome. ${ }^{21}$ Both infants had truncus arteriosus, hypocalcaemia, $T$ lymphocyte dysfunction, and facial features typical of DiGeorge syndrome. Their father was mildly dysmorphic and had an abnormal parathyroid response to a phosphate loading test but a normal cardiovascular system. Chromosome analysis in the father and his sons was normal but a molecular deletion of $22 \mathrm{q} 11$ has recently been detected in the second child in this sibship..$^{22}$ Keppen et al have described another family with dominant transmission where cytogenetic analysis did not show any abnormality. ${ }^{23}$ The infant in this family had an interrupted aortic arch type B and hypocalcaemia. His father had a history of neonatal seizures secondary to hypocalcaemia, recurrent infections throughout his life, and cardiac catheterisation at the age of 14 had shown a right sided aortic arch. There is now evidence of a molecular deletion of $22 \mathrm{q} 11$ in this man. ${ }^{22}$ A family of three children with truncus arteriosus, hypocalcaemia, and hypoplasia of the thymus and clinically normal parents has been reported. ${ }^{24}$ The authors suggested autosomal recessive inheritance in this family but an alternative explanation would be nonpenetrance, as occurred in the present report, low T lymphocyte count. T lymphocyte numbers were not measured at the time of presentation in her siblings but were within normal limits later in childhood and they had not had recurrent infections. This suggests that they 
or a group of cells with a new dominant mutation in the gonads of one of the parentsthat is, germline mosaicism.

DiGeorge syndrome is a clinical diagnosis based on finding evidence of thymic and parathyroid hypoplasia, outflow tract defects of the heart, and a dysmorphic appearance. In the family we present, the cytogenetic deletion associated with DiGeorge syndrome caused a wide variation in phenotype. The youngest girl has all four features of DiGeorge syndrome. The two boys have heart defects which are not often found in DiGeorge syndrome and the mother has no apparent cardiac abnormality. The phenotypic variation in this family and the families discussed above is evidence against DiGeorge syndrome being a contiguous gene defect. Both in the familial cases in which no cytogenetic abnormality was identified and in the families reported by Greenberg, Augusseau, and ourselves where individuals with the same apparent cytogenetic abnormality have different phenotypes the parent has the mildest phenotype and does not fulfil the diagnostic criteria of DiGeorge syndrome. It is clearly important to exclude clinical and cytogenetic abnormalities in parents of children with complete DiGeorge syndrome. In the past individuals with the milder end of the clinical spectrum were more likely to have reproduced than those with complete DiGeorge syndrome. The incidence of DiGeorge syndrome in offspring of affected individuals may, in part, be answered by the British Heart Foundation study of offspring. ${ }^{25}$

The findings in this family suggest that in some individuals with isolated heart defects, including ventricular septal defects or coarctations, the cause of the heart defect is a deletion of chromosome 22q11. This has obvious implications for the risk of recurrence in their offspring.

This work was supported by grants from the British Hear Foundation and the Borwick Trust. We also thank Mrs J Brow who carried out chromosome analysis in two of the family members. Dr J Nathans kindly provided the rhodopsin probe used as the control probe in the dosage experiments. We obtained written permission from the family for publication of the photographs.

1 Cooper MD, Peterson RDA, Good RA. A new concept of the cellular basis of immunity. J Pediatr 1965;67:907-8.

2 Freedom RM, Rosen FS, Nadas AS. Congenital cardiovascular disease and anomalies of the third and fourth pharyngeal pouch. Circulation 1972;46:165-72.
3 Finley JP, Collins GF, De Chadarevian JP, Williams RL DiGeorge syndrome presenting as severe congenital heart disease in the newborn. Can Med Assoc J 1977;116: $635-40$.

4 Conley ME, Beckwith JB, Mancer JFK, Tenckhoff L. The spectrum of the DiGeorge syndrome. J Pediatr 1979;94 883-90.

5 Moerman P, Goddeeris P, Lauwerijns J, Van Der Hauwaert LG. Cardiovascular malformations in DiGeorge syndrome (congenital absence or hypoplasia of the thymus) Br Heart J 1980;44:452-9.

6 Moerman P, Dumoulin M, Lauweryns J, Van Der Hauwaert LG. Interrupted right aortic arch in DiGeorge syndrome. Br Heart J 1987;58:274-8.

7 Van Mierop LHS, Kutsche LM. Cardiovascular anomalies in DiGeorge syndrome and importance of neural crest as a possible pathogenetic factor. Am J Cardiol 1986;58:133-7.

8 De la Chapelle A, Herva R, Koivisto M, Aula P. A deletion in chromosome 22 can cause DiGeorge syndrome. Hum Genet 1981:57:253-6.

9 Kelley RI, Zackai EH, Emanuel BS, Kistenmacher M, Greenberg F, Punnett HH. The association of the DiGeorge anomalad with partial monosomy of chromosome 22. J Pediatr 1982;101:197-200.

10 Schwanitz G, Zerres K. Partial monosomy 22 as result of an $\mathrm{X} / 22$ translocation in a newborn with DiGeorge syndrome. Ann Genet 1987;30:80-4.

11 Faed MJW, Robertson J, Swanson Beck J, Cater JI, Bose B Madlom MM. Features of diGeorge syndrome in a child with $45, \mathrm{XX},-3,-22,+\operatorname{der}(3), \mathrm{t}(3 ; 22)(\mathrm{p} 25 ; \mathrm{q} 11) . \quad J \mathrm{Med}$ Genet 1987;24:225-34.

12 Dallapiccola B, Marino B, Giannotti A, Valorani G. DiGeorge anomaly associated with partial deletion of chromosome 22: report of a case with X/22 translocation and review of the literature. Ann Genet 1989;32:92-6.

13 Anneren G, Gustafsson J, Sunnegardh J. DiGeorge syndrome in a child with partial monosomy of chromosome drome in a child with partial monosi
22. Ups J Med Sci 1989;94:47-53.

14 Mascarello JT, Bastian JF, Jones MC. Interstitial deletion of chromosome 22 in a patient with the diGeorge malformachromosome 22 in a patient with the diGeorge malf
tion sequence. Am J Med Genet 1989;32:112-4.

15 Standing Committee on Human Cytogenetic Nomenclature. An international system for human cytogenetic nomenclature (1985). Basle: S Karger, 1985.

16 Carey AH, Roach S, Williamson R, et al. Localization of 27 DNA markers to the region of human chromosome 22q11 pter deleted in patients with the DiGeorge syndrome and duplicated in the der22 syndrome. Genomics 1990;7: 299-306.

17 Miller SA, Dykes DD, Polesky HF. A simple salting out procedure for extracting DNA from human nucleated cells. Nucleic Acids Res 1988;16:1215.

18 Feinberg AP, Vogelstein B. A technique for radiolabelling DNA restriction endonuclease fragments to high specific activity. Anal Biochem 1984;137:266-7.

19 Augusseau S, Jouk S, Jalbert P, Prieur M. DiGeorge syndrome and 22q11 rearrangements. Hum Genet 1986; syndrom.

20 Greenberg F, Crowder WE, Paschall V, Colon-Linares J, Lubianski B, Ledbetter DH. Familial DiGeorge syn-
drome and associated partial monosomy of chromosome 22. Hum Genet 1984;65:317-9.

21 Rohn RD, Leffell MS, Leadem P, Johnson D, Rubio T, Emanuel BS. Familial third-fourth pharyngeal pouch syndrome with apparent autosomal dominant transmission. J Pediatr 1984;105:47-51

22 Scambler PJ, Carey AH, Wyse RKH, et al. Microdeletion within 22 q11 associated with sporadic and familial DiGeorge syndrome. Genomics 1991;10:201-6.

23 Keppen LD, Fasules JW, Burks AW, Gollin SM, Sawye JR, Miller CH. Confirmation of autosomal dominan transmission of the DiGeorge malformation complex. Pediatr 1988;113:506-8.

24 Raatikka M, Rapola J, Tuuteri L, Louhimo I, Savilahti E. Familial third and fourth pharyngeal pouch syndrome with truncus arteriosus:DiGeorge syndrome. Pediatrics with truncus art;

25 Burn J, Coffey R, Little J, et al. Recurrence risks in the offspring of adults born with major heart defects; first offspring of adults born with major heart defects; first Hum Genet 1990;47:121. 